\title{
Misconceptions, Misinformation and Politics of COVID-19 on Social Media: A Multi-Level Analysis in Ghana
}

\author{
Philip Teg-Nefaah Tabong ${ }^{1 *}$ and Martin Segtub ${ }^{2}$ \\ ${ }^{1}$ Department of Social and Behavioural Sciences, School of Public Health, College of Health Sciences, University of Ghana \\ Legon, Accra, Ghana, ${ }^{2}$ Department of Communication Studies, University of Professional Studies, Accra, Ghana
}

\section{OPEN ACCESS}

Edited by:

Fredrick Ogenga

Rongo University, Kenya

Reviewed by:

Rasha El-Ibiary,

Future University in Egypt, Egypt

Yik Chan Chin,

Beijing Normal University, China

*Correspondence:

Philip Teg-Nefaah Tabong

philgh2001@yahoo.com

Specialty section:

This article was submitted to Political Communication and Society, a section of the journal

Frontiers in Communication

Received: 03 October 2020 Accepted: 01 April 2021 Published: 05 May 2021

Citation:

Tabong PT-N and Segtub M (2021)

Misconceptions, Misinformation and Politics of COVID-19 on Social Media: A Multi-Level Analysis in Ghana. Front. Commun. 6:613794. doi: $10.3389 /$ fcomm.2021.613794
Background: Ghana developed an Emergency Preparedness and Response Plan (EPRP) in response to the Severe Acute Respiratory Syndrome Coronavirus (SARS CoV-2) pandemic. A key strategy in the EPRP is to mobilize national resources and put in place strategies for improved risk and behavioral change communication. Nonetheless, concerns have been raised on social media about COVID-19 misinformation and misconceptions. This study used social media content to determine the types, forms and the effects of the myths, misconceptions and misinformation in Ghana's COVID-19 containment.

Method: The study was conducted in three phases involving the use of both primary and secondary data. Review of social media information on COVID-19 was done. This was complemented with document review and interviews with key stakeholders with expertise in the management of public health emergencies and mass communication experts $(N=18)$. All interviews were transcribed verbatim and analyzed using NVivo 12.

Results: The study showed a changing pattern in the misconceptions and misinformation about COVID-19. Initially myths were largely on causes and vulnerability. It was widely speculated that black people had some immunity against COVID-19. Also, the condition was perceived to cause severe disease among the elderly. These misconceptions served as risk attenuators among Ghanaians, especially the younger generation. As the infection evolved in the country, another misconception emerged that the hot climate in Africa inhibited viral replication and transmission only to be followed by speculations and conjectures that COVID-19 was being used as a biological weapon to target developed economics. For the management of COVID-19, the use of local remedies such as Neem tree (Azadirachta indica) and herbal preparation also emerged. Myths about the efficacy of locally manufactured gin (akpeteshie) and hydroxychloroquine as prophylaxis led to abuse of such substances. Interview segments revealed the use of myths to propagate political agenda in the country.

Conclusion: The study concludes that COVID-19 misconceptions and misinformation are widespread and cover the course of the condition. These myths necessitate culturally sensitive health communication strategies that take into account local perceptions of COVID-19 in order to tackle the circulation of misconceived messages about the pandemic in Ghana.

Keywords: COVID-19, myths, social media, Ghana, misinformation, misconceptions, politics 


\section{INTRODUCTION}

A novel human coronavirus, Severe Acute Respiratory Syndrome Coronavirus 2 (SARS-CoV-2), which causes a disease known as COVID-19, was identified in China in December 2019 (Wang et al., 2020). The incubation period has been reported to range from 2 days to 21 days, but with many people reporting symptoms within 14 days (Lauer et al., 2020).

On 11th March 2020, the World Health Organization (WHO) declared COVID-19 a global pandemic due to the deep concern both by the alarming levels of COVID-19's spread and severity (Hageman, 2020). Ghana confirmed the first two cases of COVID-19 on 12th March 2020. Since then, the case incidence has risen dramatically. As of 22nd September, 2020, a total of 46,062 cases have been confirmed with 297 deaths. At least, a case has been confirmed in all the sixteen regions in the country. In response to COVID-19 pandemic, government rolled out Ghana's Emergency Preparedness and Response Plan (EPRP) with the objective to "enhance surveillance system and build response capacity to detect, contain, delay and respond to a COVID-19 outbreak in Ghana." A key strategy in the EPRP is to mobilize national resources and put in place strategies for improved risk and behavioral change communication using local and internetbased media.

Ghana's media landscape has its antecedents from colonial experiences under the British rule. Newspapers were published by the governor of the Gold Coast (Now Ghana) in the 19th century. Radio was introduced by colonial authorities on the occasion of the Silver Jubilee of King George V, and was used to communicate with colonial residents and privileged native elites. Incidentally, newspaper, later augmented by radio, were also effective tools in the liberation efforts by natives of the Gold-Coast (now Ghana) from colonial rule.

Until the dawn of the internet, radio was the most-used source of news among Ghanaians with about 500 authorized radio broadcasting stations (National Communications Authority, 2017; Government of Ghana, 2018). While television which was introduced in Ghana in the 1950s, had a spark of excitement among Ghanaians, radio continued to be a more accessible medium to Ghanaians than television. The leading role of radio as the mostly used medium, however, has now been overtaken by the internet which has more than 10 million active users in Ghana (Myjoyonline, 2018). Social media has become an essential platform for engagements, especially among the youth and the educated class, not only to keep themselves connected virtually, but to keep public officials in check (Gyimah-Boadi, 2018). Social media has also been used to address health issues such as HIV/AIDS and Ebola.

The internet, or more specifically the websites on the World Wide Web, is continuously changing because of technological developments. One of this information sources that has revolutionized the world is social media. More and more internet users now spend lots of time on social media websites (Kaplan and Mazurek, 2018). Social media are online platforms on which user generated content can be shared. Facebook, Twitter, WhatsApp, and Telegram are popular and broadly used examples of these participative platforms in which users can read and post different types of content. People use social media as an alternative source for evidence-based information on health (Kass-Hout and Alhinnawi, 2013). These same social media could also be used to spread myth, misconceptions and misinformation (Moorhead et al., 2013). Recently, social media has been identified as a possible place to conduct rumor surveillance in public health which can hinder the uptake and impact of health intervention (Fung et al., 2015; Joshi et al., 2020).

Ghanaians enjoy constitutional liberties such as freedom of speech and freedom of the press with a very vibrant media. The media has been documented to play an important role in crisis management (Ghassabi and Zare-Farashbandi, 2015). The general public have increasingly used social media during crises and health emergencies such as the COVID-19 pandemic. As a result crisis communication professionals need to understand how to strategically optimize these tools (Jin et al., 2014) as they can either impede or facilitate behavioral change practices.

With the advent of smart phone, social media has become an important source of information and news in Ghana (CDD, 2020). Social media has redefined how Ghanaians access information, and doors have been opened for a better distribution of content and a wider reach of audience. Social networking sites including Facebook, Twitter, YouTube, Blogs, LinkedIn, Google Plus, WhatsApp, Telegram, smart phone applications, as well as news delivery sites; and other online platforms are widely used in Ghana. As of January 2020, Ghana registered approximately six million active social media users, up from 5.8 million in 2019 with WhatsApp as the most popular platform in use (Sasu, 2020). This high penetration and use of social media make this platform very suitable for distribution of myths, misconceptions and misinformation about COVID-19. This study therefore used social media content to determine the types, forms and effects of myths, misconceptions, and misinformation about COVID-19 on social media. This was done to provide evidence required to better handle the communication aspect of COVID-19 containment in the country.

\section{THEORETICAL APPROACH TO STUDY}

This study relies on the foundations of Social risk amplification and attenuation theory (Kasperson and Kasperson, 1996). The concept of social amplification of risk is based on the proposition that events pertaining to threats interact with psychosocial, institutional, and cultural processes in ways that can either heighten or attenuate individual and social perceptions of risk as well as shaping of human behavior. Behavioral patterns, in tum, generate secondary social or economic consequences. These consequences may directly affect humans or their environment. There could also be indirect impacts such as loss of trust in institutions or alienation from community affairs (Kasperson et al., 1988). Such secondary effects often trigger demands for additional institutional responses and protective actions or conversely (in the case of risk attenuation), place impediments in the path of needed protective actions.

In adopting this theoretical approach, we recognized that COVID-19- related information and risk are socially 
constructed and communicated to others through various platforms including social media. The consequences of these communication efforts may lead to individual perceptions about the information and inform behavioral changes. The Kasperson's social amplification of risk framework therefore highlights factors that influence risk perception, which include examining the characteristics of the risk event and how it is interpreted and communicated by social actors (Kasperson and Kasperson, 1996) and government's risk management organizations such as Ministry of Health and Ghana Health Service structures. According to the theory, information is communicated through social amplification stations. The social amplification stations produce and transmit information through communication networks such as media, telephones and direct conversations. Each recipient then engages in amplification processes, thereby acting as an amplification station for risk-related information. These socially built risk messages are consequently interpreted and acted on by individuals based upon one's attention, personal characteristics and attitudes (Kasperson et al., 1988). It has indeed been demonstrated that a combination of trust, perception and emotions play a significant role in shaping risk perceptions during conditions of uncertainty such as COVID-19 pandemic.

\section{MATERIALS AND METHODS}

\section{Study Area}

The study was conducted in Ghana. Ghana practices a democratic governance system with the 1992 constitution being the supreme law of the country. The country's constitution and democratic mechanisms dictate transparency of decision-making processes and thereby determine the degree to which politicians are held accountable. The 1992 Constitution is based on the principle of separation of powers, as well as a system of overlapping personnel, functions, and powers, resulting in a hybrid of the Presidential and Parliamentary systems of government. Three arms of government are recognized by the 1992 constitution of the Republic: Executive headed by the President, Parliament headed by Speaker (who is nominated by the majority in Parliament) and Judiciary headed by the chief Justice (nominated by the President and approved by Parliament), (The Constitution of Ghana, 1992). An executive president has the mandate to appoint ministers in-charge of various ministries.

The organization, management and operations of the health sector in Ghana are governed by parliamentary legislations. In 1996, The Ghana Health Service (GHS) and Teaching Hospitals Act (ACT 525) was passed by parliament (Republic of Ghana, 1996). This Act (ACT 525) separated the governance and policy from the operational aspects of health service delivery in Ghana. The Act essentially led to the creation of the Ghana Health Service as an implementation agency of the Ministry of Health policies. The policies are then implemented by national, regional, district and sub-structures of the GHS. The regional, district and community levels, health facilities are established to provide primary and secondary health care services including health promotion activities. An earlier study in Ghana during the 2014 West African Ebola outbreak reported that the health system has potential to adequately prevent, respond to and contain disease outbreaks (Agyepong, 2014) despite health worker perception that the country's preparation was inadequate (Adongo et al., 2017).

Following the outbreak of COVID-19 in Ghana, a new bill called the Imposition of Restriction was submitted to Parliament and passed into law (Republic of Ghana, 2020). This law mandates the president to impose restriction such as lockdown and implement other emergency COVID-19 emergency measures when necessary. The bill also allows the president to take remedies to enhance emergency health care in the country. In addition, a National Technical Coordination Committee team was formed to lead the response. The government also activated activities under the Emergency Operations Center (EOC) established with support from the World Bank. These include risk communication, point of entry surveillance, laboratory diagnostics capacity building for case management and coordination of preparedness and response actions. Weekly updates are also organized.

\section{Study Design and Analytic Approach}

This study was conducted in three phases. In the first phase, we reviewed government's COVID-19 response documents to identify the strategies put in place to manage the communication aspect of COVID-19 containment. Netnography was then employed in the second phase of the study to document myths and misconceptions on social media. Netnography is a form of ethnography conducted online or use of social media through a humanist participant-observational research approach (Kozinets, 2015). We conducted in-depth interviews with stakeholders in the third phase of the study (Figure 1). The data collection was done between 12th March 2020 and 31st September, 2020.

\section{Data Collection Methods and Tools}

The data collection method was informed by the Kasperson's social risk amplification and attenuation theory. This theory emphasizes the role of sources of information and channels of transmission as critical communication. Guided by this we employed main data collection strategies in this study; review of COVID-19 response plan and related documents with focus on communication strategies, social media content analysis (netnography) and in-depth interviews.

\section{Document Review}

We reviewed documents which were developed in response to COVID-19. Our focus on the review was on communication and measures put in place to reduce the conceiving and spread of myths and misconception, specifically on social media. The review was guided by the following research questions:

1. What COVID-19 information and communication strategies are used?

2. Does the document specifically address issues concerning myths and misconceptions?

3. Does the document recognize social media as essential platform for the spread of myths and misconceptions?

4. What strategies have been mentioned to reduce conceiving and spreading of myths and misconceptions? 


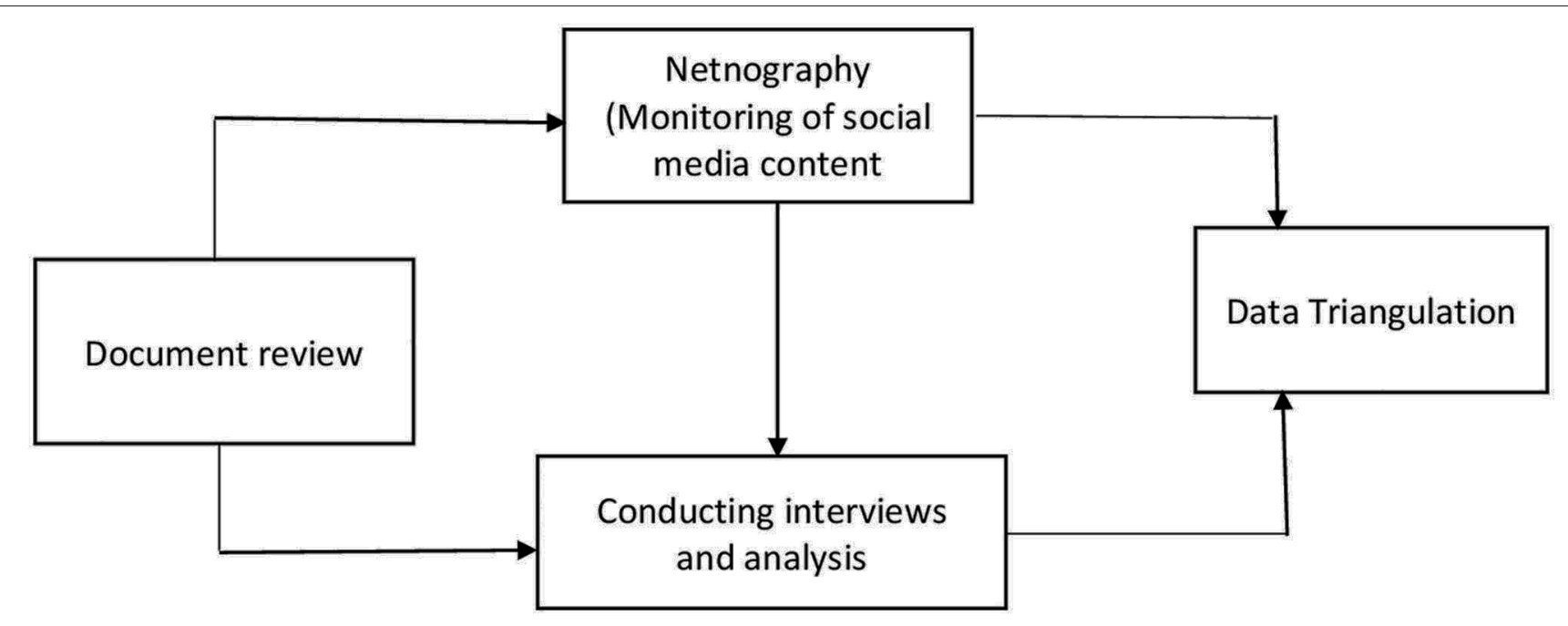

FIGURE 1 | Pathway for conducting the study on myths and misconceptions on COVID-19 in Ghana, 2020.

Some of the documents that were received include Ghana's Emergency Response and Preparedness Plan; Imposition of Restrict Law; UNDP Programmatic Offer for COVID-19 Response in Ghana.

\section{Content Analysis}

Content analysis involved analyzing posts across five social media platforms: WhatsApp, Telegram, Instagram, Facebook, and Twitter. Instagram, Facebook, and Twitter and all posts were extracted using screenshot methods. Research assistants were trained to monitor and collate all social media content related to COVID-19. We also monitored the Twitter handle of the minister of communication who provided responses to myths that were circulating in social media. We also used keyword searches on Twitter (Pulsar search tool) and Facebook for the specific period of the study and location (Ghana). In addition, we used the Instagram business tool which is linked to Facebook to collect all post on Instagram timelines and other social media platforms. Furthermore, we used the NCapture on NVivo program for the extraction and segmentation of Twitter data from a web browser following the recommendations of Edward and colleagues (Edwards et al., 2013).

For media releases from government officials which were shared, the entire document was retrieved and added to the data set. Daily monitoring was done throughout the study period. The monitoring was done by the authors and trained research assistants. Daily Zoom meetings were held to discuss new misconceptions.

\section{Interviews}

A purposive sampling technique was used to select participants for the interview component of the study. We used the Ghana ERPA and document review to identify the key stakeholders in the communication aspect of COVID-19 response. ERPA clearly identified and defined the role of various institutions. We contacted the institutions who then selected a participant for us to interviews. The selected individuals were mainly focal persons in COVID-19 response or were at the forefront of instituting measures aimed at contributing to Ghana's containment efforts (Table 1).

We prepared an interview guide before conducting semistructured interviews to ensure that the same basic lines of inquiry were pursued. The topic guide elicited information on communication strategies used, misconception, myths and misinformation about COVID-19. Further, we collected information on role of social media, and strategies to reduce spreading of misconceived information.

The interviews were all conducted in English, through phone and face-to-face basis. Physical distance was maintained throughout the face-to-face interviews at the offices. Besides, both the interviewee and interviewer wore a face mask. It took between 30 and $45 \mathrm{~min}$ to complete an interview session. All interviews were conducted by one of the authors (PT-NT). After the interview, a summary of the interaction highlighting key points was done to validate the data as a form of member checking (Birt et al., 2016; Tabong et al., 2018).

\section{Data Analysis}

The analytical approach that we adopted was critical discourse, content and frame analyses to both intensify and interrogate the myths and misconceptions frames used in the social media discourse. In undertaking a frame analysis of the social media content, we identified which frames the social media gave salience to. Frames were quantified in terms of frequency and then analyzed in depth. We employed the Kasperson's social risk amplification and attenuation to identify the frames. We looked at the source of information, the channel, the content of the message, examined the audience for this message and finally examined the effects of the message on human behavior (COVID-19 preventive interventions). 
TABLE 1 | Institutions where participants were selected for the study.

\begin{tabular}{ll}
\hline Institution & Number interviewed \\
\hline Ministry of Health & 1 \\
Ministry of Information & 1 \\
Ministry of Communication & 1 \\
Ghana Health Service & 1 \\
National Commission for Civil Education & 1 \\
Ghana Journalist Association & 1 \\
Coalition of Non-government Organizations in Health & 1 \\
Civil Society Organization & 1 \\
National Media Commission & 1 \\
Ghana Medical Association & 1 \\
Ghana Registered Nurses and Midwives Association & 1 \\
Information Service Department & 1 \\
Academia & 1 \\
Multinational Organizations & 2 \\
Community members & 3 \\
Total & 18 \\
\hline
\end{tabular}

In conducting a thematic frame analysis on the myths, misconception and interviews, we also explored the frequency of themes and concepts mentioned by the interview subjects, in order to identify the most salient themes. The qualitative interviews were recorded using an audio recorder and transcribed verbatim. We reviewed the social media content and transcripts and developed a codebook which served as a guide for the thematic analysis (Bowling, 2014). The codebook was developed by one of the authors (PTNT) and reviewed by second author (MS). All myths and misconception and transcripts were imported into NVivo 12. NVivo is one of the Computer Assisted Qualitative Data Analysis Software (CAQDAS) and is well designed for managing qualitative and presenting qualitative data as chart and graphs for easy visualization (Zamawe, 2015). Hybrid inductive and deductive framework were used in the coding (Fereday and MuirCochrane, 2006). Conceptual dimensions of the Kasperson and Kasperson social risk amplification and attenuation theory, and social media content guided the preliminary development of the codebook and nodes in NVivo. The key constructs of the theory include: sources of information, contents, media that is used to communicate the information, and how these interact to either amplify or attenuate the individual perception of risk and subsequent behavior. This was then revised to include the emerging themes from the data. We created nodes from the codebook. Each transcript and social media content was opened in the software, coded and reviewed. During coding, memos were also created for documenting our thoughts, doubts and insights that were emerging. We used the queries function in NVivo to draw a word cloud to show the various misconceptions about COVID-19 in Ghana. Coded sections were regrouped into relevant categories and themes for presenting the results. Data triangulation strategy was used to strengthen the findings (Teddlie and Tashakkori, 2010) of the study based of the multiply data sources. Direct quotations were used, where appropriate, to support the themes.

\section{RESULTS}

The study found a number of misconceptions covering various aspects of the COVID-19. These misconceptions have been summarized on the word cloud on Figure 2.

Document review clearly shows that providing accurate information about COVID-19 was recognized as key in containing the outbreak. For example, it has been documented as one of the strategies in the containment:

Support dissemination of accurate information on prevention and response to hard-to reach areas and groups through various mediums including billboards (UNDP, Ghana).

\section{Early Misconceptions About Vulnerability and Prevention}

Before Ghana had its first confirmed case of the COVID-19 on the 12th March, 2020, it was widely circulated on social media that the virus (SAR-CoV-2) could not survive in the hot climate in the country. This speculation partly originated from an interview which was granted to a media house by a medical practitioner which was misconstrued. This myth served as risk attenuator as people felt the disease would not be imported into the country.

To counter the negative effects of this myth, government issued a press release. Conducting Interviews with medical practitioners with expertise in infectious disease, it was emphasized that warm weather does not offer protection against survival of the virus. One participant shared his opinion as follows:

\footnotetext{
Let no one kid themselves that our environment protects us, our genes protect us or the humidity protects us; we already have some for coronaviruses in the country which give us other form of cold. So that assertion is incorrect. It was misunderstanding from an interview one of my colleagues granted at Korle-Bu Teaching Hospital" (IDI-3).
}

In addition, it was widely circulated that black people have immunity against the virus. This belief served as risk attenuator with low adherence to COVID-19 prevention measures. A communication expert shared this in an interview:

The myth circulating that the virus cannot affect the black race makes some Ghanaians feel they cannot get the condition. This negatively affects the compliance to the wearing of face/nose mask. The government and health experts must disabuse this myth immediately" (IDI-3).

A community member corroborated this in an interview as follows:

In the community, people are not using the face mask because of the believe that black people cannot get the condition (IDI-17). 


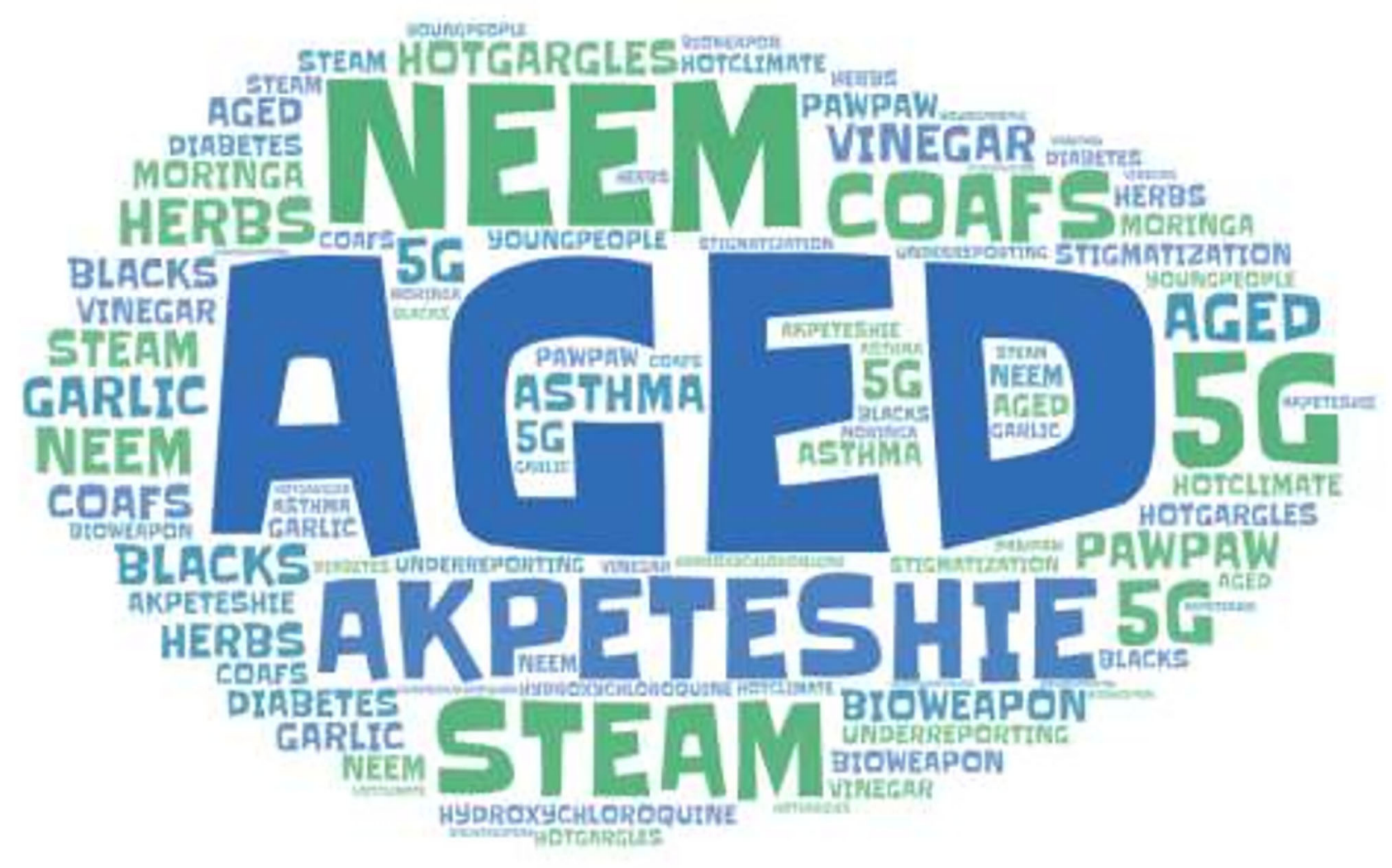

FIGURE 2 | Word cloud of COVID-19 misconceptions in Ghana, 2020.

Another misconception was that the disease only affects older people while younger individuals were less susceptible to the disease. However, as the infection continued to evolve, this myth was found to be untrue when younger people got infection and some even died of the condition. In an interview with health experts it was emphasized that everybody irrespective of your age can be infected as follow:

\footnotetext{
"From global data, more older people are infected with high mortality among such groups of people but it doesn't mean younger people are completely protected from the condition and death" (IDI-7).
}

It was also widely circulated that only people with chronic condition such as hypertension, diabetes mellitus and asthma are at risk of developing the disease condition. Whilst this was in circulation, it also emerged that eating of garlic and drinking of apple cider vinegar was also widely reported as a preventive measure against the disease condition.

Furthermore, drinking of locally manufactured alcoholic drink (akpetseshie) was circulated on WhatsApp and Facebook as effective in the prevention of the condition. As health education focused on the use of alcohol-based hand sanitizer, it was misconstrued that heavy drinking of alcohol could kill the virus in the blood stream. Interview segments showed that this could not offer any form of protection. A participant shared the following in an interview:

\begin{abstract}
Akpeteshie on your hands might act as a hand sanitizer but if you drink it, you're just going to get drunk and probably end up with the coronavirus anyway. This does not offer any protection and may rather reduce your immune system thereby increasing your risk of infection and severity of the condition (IDI-6).
\end{abstract}

\section{Myths, Misconceptions and Misinformation About Causes of Covid-19}

It was widely circulated that COVID-19 was a biological weapon to bring down countries who were competing with China for both socio-economic and control of developing countries. This myth became so widespread and accentuated by the delay in the importation of the disease condition to Ghana. A community member shared her opinion as follows:

I heard from social media that it was developed in a laboratory in China to attack developed countries. So, it will not come to Ghana (IDI community member).

Another misconception was the belief that it was caused by a $5 \mathrm{G}$ networks. This misconception emanated from a video which was widely circulated on WhatsApp, Facebook and Telegram 
in Ghana. In this video, a televangelist emphasized that SARSCoV-2 was created as a $5 \mathrm{G}$ and released to end the world. In an interview, a health worker indicated there was no data to support this assertion:

The virus has nothing to with 5G... I saw the video of the preacher who linked it to end time but it's false. It's a myth that should not even worry our heads (IDI-7).

Before the confirmation of the first two COVID-19 cases in the country, there was low information, education and communication about the condition. Interviewees indicated these accounted for the high-level misconception on the cause of the condition. The Health Promotion Directorate was supposed to inform people on the behavioral change communication aspect of the COVID-19 response. However, this role was largely performed by the Minister for Information, who, in the opinion of health experts, weakened the existing structure for providing education and information on COVID-19. Decentralization of the information and communication apparatus was done with little involvement of health promotion officers. Two participants shared their views as follows:

You see, the information and communication aspect of the COVID19 is weak...technocrats have been relegated to the background. So, the existing Ghana Health structure which should spearhead this is not involved. This allows room for the spread of myths and misconception and that is the problem we are facing (IDI-2).

The emphasis on health education and information dissemination focus on the weekly press briefing organized by the Minister of Information without a clearly defined audience. Even social media which is one the fastest and widely used channel for providing information was not used initially. Now that people have been are fed with a lot of misconceptions about the condition, it is now being considered with threats from the Minister of Communication that they will block people who intentionally spread falsehood and misconception about COVID-19 in the country (IDI-7).

Nonetheless, mass media and social media were listed as communication channels which would be used for COVID-19 in the ERPP plan for Ghana as stated:

Mass communication and social media will be key in bringing the message to individual households using various methods including community van announcements for community sensitization (ERPP, p. 8).

The Emergency Response and Preparedness Plan (ERPP) recognizes the need to develop a risk communication guidelines and policy for implementation at all levels as follows:

Currently there are no policies, procedures and mechanisms to follow while engaging the public during an emergency (pp. 5-6).

These guidelines and policies were not developed and this accounted for the weakness in the COVID-19 communication. One interviewee shared this in an interview:
The country needs a communication guideline and policies for health emergencies such as COVID-19. This is weakest part of COVID-19 response. Every government ministry tries to do something and in the process the communication is not well coordinated. We need as country to allow health communication experts to lead the process (IDI-11).

\section{Myths, Misconceptions and Misinformation About Use Personal Protective Equipment (PPE)}

Whilst the government was at the forefront of advocating for people to use face/nose masks, another misconception emerged which affected compliance. A post which was widely circulated on WhatsApp and Facebook sought to portray the use of these nose and face mask could result in fainting or ill-health. According to a post the use of face/nose mask could reduce blood oxygen level whilst increasing the accumulation of carbon dioxide. This myth led to increase demand and use of face shield only which can offer little protection against airborne infections. A participant in an IDI shared his view as follows:

"People use the face shield because of the discomfort some people claim is associated with the use of the face mask. Now face shields are very expensive and are of more demand" (IDI-16).

Recognizing the widespread use of face shield only, the Ghana Medical Association and West Africa College of Physicians and Surgeons issued a statement to counteract the myth on the negative effects of using face shields only on 15th July, 2020.

The use of face shields alone (without face mask) does not give the user the needed protection against COVID-19....As medical doctors, especially surgeons, we wear face masks all the time in the course of work and no such derangement have been observed.

\section{Myths, Misconceptions and Misinformation About Management of COVID-19}

The wide speculation about the use of hydroxychloroquine as prophylaxis and management on social media in Ghana led to panic buying of the drug from pharmacies. This resulted in shortage of this drug in the market. This became an issue of concern for the Pharmaceutical Society of Ghana (PSGH). The president of this association had to issues a press release on 20th March, 2020 to caution members of the society from selling drugs to people without prescription as follows:

It has come to the attention of the leadership of Pharmaceutical
Society of Ghana (PSGH) that with the news that United States
is using hydroxychloroquine to treat COVID-19, there is
rush by many to acquire these medications from community
pharmacies. I encourage my colleague pharmacies not to dispense
hydroxychloroquine tablets to clients without valid prescription
(President, PSGH).

Concerns were also raised about the negative effects of chloroquine abuse. This health expert in an interview explained the negative effects of the abuse of hydroxychloroquine as follow: 
There are a lot of people with hepatitis B in Ghana, a lot of people with chronic liver diseases have to be careful using it. People with seizures, or people who are taking anti-epileptic medication should be very careful, it can cause irregular heart beat and thus should only be used in the hospital setting (IDI-7).

Another misconception on management was the use of Neem tree (Azadirachta indica) leaves. It was widely circulated on WhatsApp and Facebook that boiling Neem tree leaves and using it for steam inhalation could kill the virus on the upper respiratory tract. This was believed to prevent the virus from descending into the lower respiratory tract to cause more severe condition. This myth led to mass harvesting of Neem tree leaves across the country. Daily steam inhalation became a norm among some Ghanaians. A community member shared his experience in an interview:

"I do daily inhalation and bathing of water from boiled Neem tree...it is very good for conditions that affect the respiratory system. People even come to my house to beg for Neem tree leaves" (Community member 2 ).

Inhaling stream from boiled Pawpaw leaves also emerged and was widely circulated on WhatsApp, Facebook, Telegram and Twitter. In general, it was widely circulated in social media that steam inhalation and hot gargles could provide some protection against infection and cure. This was presented as a strategy that was used to overcome the infection in Wuhan China (Figure 3).

Again, Some Ghanaians engaged in daily steam inhalation as a preventive measure as follows:

I have seen the WhatsApp in circulation advising people to boil pawpaw leaves and inhale in the steam from it and also bath the water (IDI-14).

The emergence of the misconception that a locally manufactured herbal dietary supplement CoA FS was effective for the management of COVID-19 led to mass rush for it. This created an artificial shortage in the market and an increase in the price of the supplement. This misconception originated from a news item which was widely circulated on social media. This was published by the online media portal, dailymailafrica.com, on March 25, 2020, which sought to suggest that Noguchi Memorial Institute for Medical Research (NMMR), one of the centers for testing the Coronavirus (Covid-19) disease in Ghana, has confirmed COA FS as cure for COVID-19. This news item titled: "Noguchi finally 'approves' Ghana-made drug to fight Coronavirus" refers to an interview the Director of the Medical Institute, Professor Abraham Kwabena Anang, granted on the Covid-19 pandemic. Since its publication, the story has been widely shared across a number of social media platforms with many people sharing it on twitter (Figure 4).

On April 7, 2020, authorities of the Institute debunked this assertion on their twitter handle as follow:

The University of Ghana, Noguchi Memorial Institute for Medical Research, hereby inform the general public that it has not independently tested or verified that COA FS can treat COVID-19.
A post-market surveillance conducted by the Food and Drug Authority of Ghana on the COA FS showed some of the products were contaminated with bacteria such as Escherichia coli. The manufacturer was subsequently instructed to recall and destroy the products in the market. The company complied with the directive and issued a press statement on the 25th May, 2020 as follows:

We wish to state that COA Herbal Center, acting upon the directive of the FDA has since ceased production, recalled our products from the market, and submitted the same to the FDA which was safely disposed of on the 22nd of May, 2020.

\section{Misconception About Post Recovery Transmissibility}

As the disease evolved and management of the condition improved with several recoveries, a new misconception about infectiousness of recovered individuals emerged. This resulted in stigmatization and social isolation of people who recovered from COVID-19. As a result, recovered COVID-19 patients in their initial stage of family integration had to practice some cautious social distancing from family members, close relatives and friends. An interviewee shared her opinion on this as follows:

Now our communication should target the misconception that people who recover from the condition are still infectious. It is creating a problem in the re-integration of recovered people (IDI16).

As a consequence of this myth, it was widely reported in both social media, radio and television that recovered COVID-19 were stigmatized. Some were even ejected from their rented apartments and turned away from shops even after testing negative. One recovered person indicated he was ostracized by the local community because they felt he was still infectious. However, interviews with health experts show that once they tested negative, they have no risk of infecting other people. A health expert shared his opinion on this:

The people who test negative and have been declared as recovered pose no risk to community. However, this myth has resulted in stigmatization and discrimination against people who recover from COVID-19 (IDI-7).

This misconception was fueled by social media reports that health experts were discharging patients because COVID-19 treatment centers were full. The belief that government was reporting higher recoveries for political reasons also heightened the suspicion that some recoveries were only asymptomatic and could still transmit the infection. One study participant shared his views as follows:

There appears to be a mistrust with respect to handling of COVID19. Some people feel figures being reported are massaged especially the recoveries. So, people are still afraid of people who have been declared as recovered. You know the delay in receiving test results is one of the reasons for some of these misconceptions (IDI-13). 


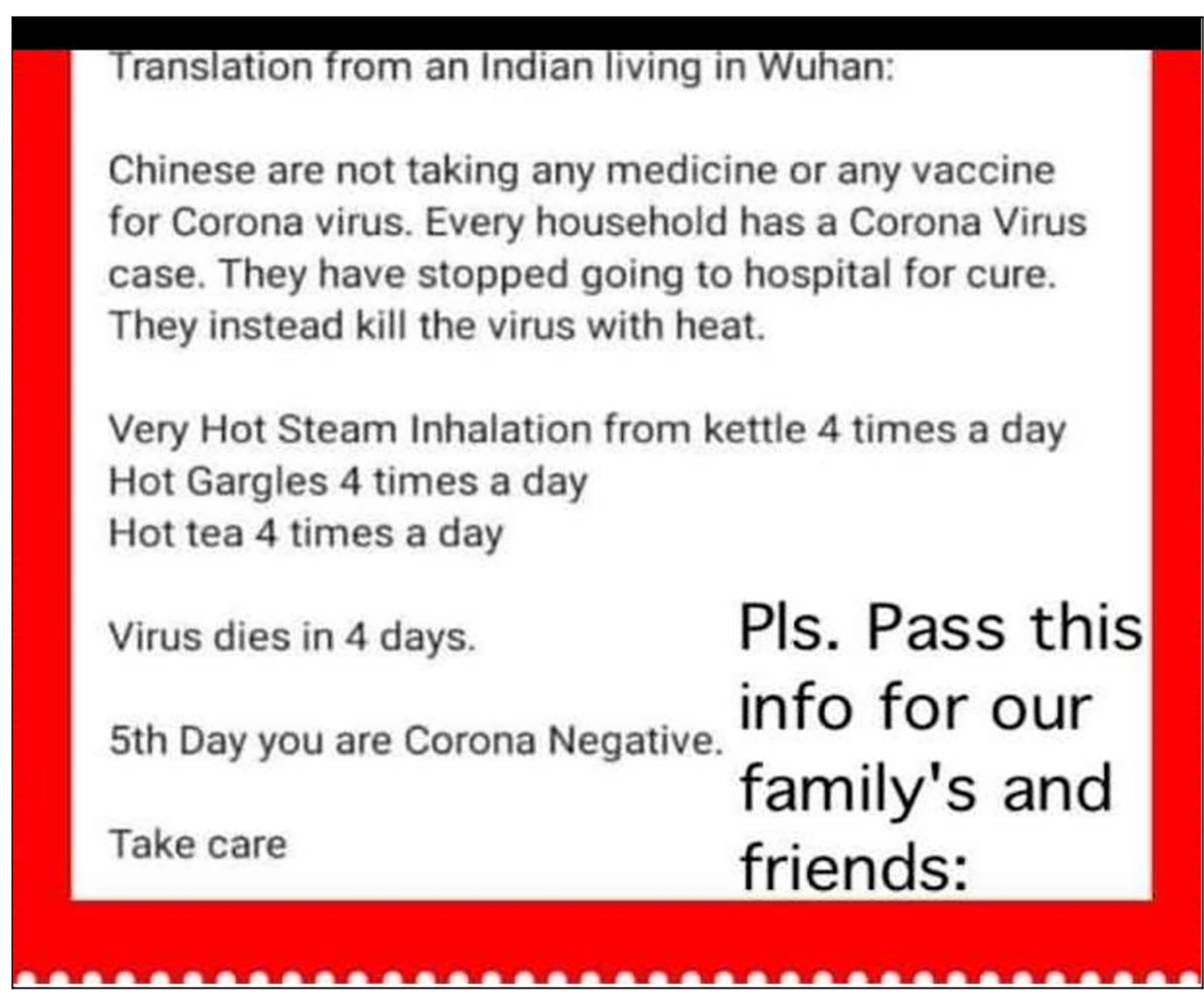

FIGURE 3 | Misconception about protective effect of steam inhalation.

As a result of this misconception, a health manager had to issue a position statement that the new COVID discharge policy was to de-isolate asymptomatic cases 14 days after initial positive test. This according to the position was based on WHO new recommendation based scientific evidence. An excerpt from this release which was widely circulated in WhatsApp, Twitter and Facebook states:

\begin{abstract}
"Unpublished data from the first 146 recovered COVID-19 patients in two centers in Accra found that the average time to viral clearance for most of the patients was 14 days. At a special meeting in Kumasi, of all 16 Regional Directors of Health Service, members of the National Case Management team, Head of the National Public Health Reference and with inputs from other experts, we deliberated to arrive at a proposal on De-isolation or Discharge in the context of Ghana" (Ghana Health Service, June, 2020).
\end{abstract}

\section{Politics in Ghana as Engine for Spreading Myths and Rumors on COVID-19}

The political system in Ghana is riddled with high patronage, resulting in extreme competition for political capital. With the
New Patriotic Party leading government during this pandemic, there is an ongoing competition for political advantage toward the forthcoming elections in December 2020. As the pandemic evolved, the opposition National Democratic Congress put together a technical team. This, in the opinion of others, resulted in the dissemination of conflicting positions about COVID-19 in social media. The opposition party (NDC) were the first to raise concerns about incumbent government's management of information and communication relating to COVID-19. In this regard, it was widely circulated in social media that government was reporting high figures of infection to gain World Bank COVID-19 relief fund.

"There is generally mistrust between the incumbent government and opposition and this is fueling the misconception about the condition. The opposition constituted a parallel COVID19 support team. So, you have two groups of people providing different information. So, the ordinary Ghana become confuse and rely on the infodemic in social media which largely are misinformation" (IDI-14). 


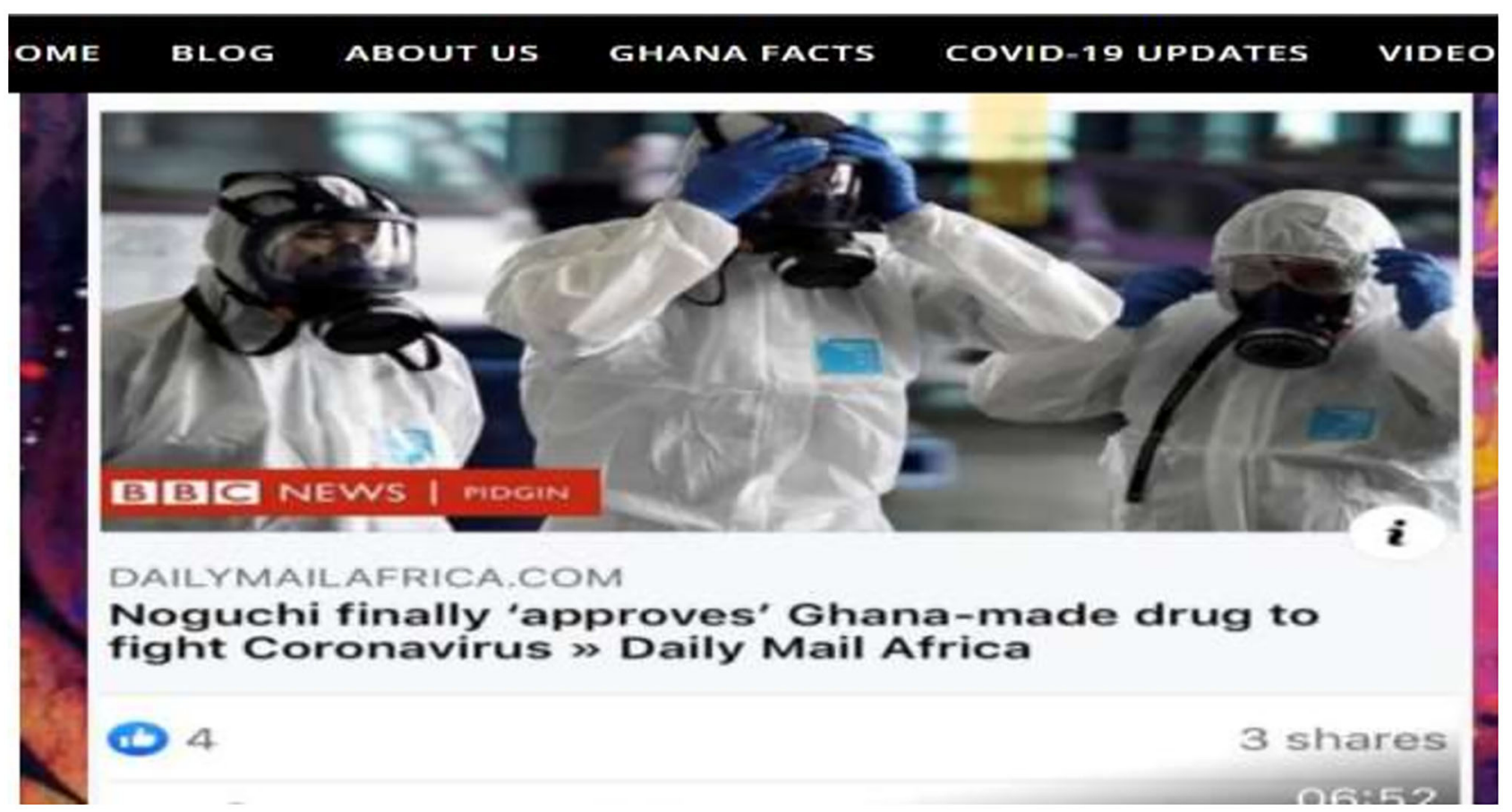

FIGURE 4 | A BBC news item on a misconception about COA FS approval for the management of COVID-19, 2020.

As the pandemic evolved, it was circulated that government was under-reporting the number of cases, recoveries and deaths to show that the country was managing the pandemic well. The pinnacle of this occurred on the 5th May, 2020. During a press conference, with national total of confirmed cases at 2,719 and 294 recoveries, with 18 deaths, it was announced that the country COVID-19 cases had reached its peak in the country as follows:

We are not out of the woods yet. We are at the peak of the curve, but yet to come down, and we urge Ghanaians to adhere to the preventive measures put in place so that we can see an early decline in infections (Director General, GHS).

However, the opposition party and many health experts disagreed with the position of the GHS. For example, an interview with a health expert with Center for Democratic Governance which was widely circulated on social media state:

"The fact that you are testing more means you will identify more but it also means the disease is spreading more and that's why in our opinion we are nowhere near our peak."

Many attributed this statement to political manipulation in order to ease restriction imposed by the government and pave way for the National Identification Authority to complete a mass registration and issuance of Ghana card as well as the Electoral Commission to conduct a new voters registration exercise for the 2020 presidential and parliamentary elections. An interviewee stated as follows:

\begin{abstract}
"You see the myth that COVID-19 infection had peaked in Ghana was simply a political decision to enable the government ease the restrictions for the voters registration.... when some of us were interviewed and we indicated Ghana was not near peaking, we were attached but we have all now seen that the announcement had no basis. How many times have we peaked since the first announcement?" (IDI-17).
\end{abstract}

Later, the government developed a COVID-19 tracker as a strategy to determine possible contacts of people who test positive. The COVID-19 Tracker App, through the common platform of mobile networks, was to be used to trace contacts of persons infected by the virus, show where they have been in recent time, through various telephone related data, and link such people to health professionals for urgent action to be taken. However, there was misconception that this app was a device to monitor, track people's mobile transaction and invade the privacy of people.

\section{DISCUSSION}

This study used social media content and interviews to document COVID-19 related misconceptions in Ghana. The study found that COVID-19 related myths and misconceptions were very common in Ghana and hindered containment efforts by public health authorities. In the face of this previously unknown virus, many Ghanaians have been turning to social media platforms in an attempt to stay informed about the latest developments and connected to friends and family. However, the major challenge had been how to verify the 
authenticity of information. As has been demonstrated, myths and misconceptions were rife and transmitted very quickly through social media. Many people may be spreading these misconceptions unintentionally on social media because they fail to stop and think sufficiently about whether the content is accurate. Lack of credible information sources and mistrust about the information from health authorities, as was the view of some Ghanaians, also accounted for the widespread of the misconceptions. The belief that government censors information about COVID-19 partly aggravated the situation in the country. The spread of misconceptions on COVID19 was not limited to Ghana as it has been reported across the world. To reduce and minimize the spread of misconceptions, leading social media companies introduced a system to flag, curb and remove myths and misinformation across their platforms. Nonetheless some contents still slip through the cracks. These myths and misconceptions can be dangerous, even deadly, during outbreaks such as COVID-19. In the fight against Ebola in the Democratic Republic of Congo, for instance, many did not believe the disease exists nor associated its spread with healthcare workers and therefore avoided seeking treatment (Mian et al., 2019). Given the way social media can be used to spread misconceived information in times of crisis, it is vital for countries to plan a response and share information strategically via social media in order to control the information and avoid a worsening the situation.

The misconception about the use of steam has its roots in traditional management of flu in Ghana. Steam inhalation is something that has been used to cure cold over the years as it relieves the person of nasal congestions and other flu symptoms. Although steam inhalation can provide relief for nasal congestion (Little et al., 2016), it has not been established it can protect one against COVID-19 infection as was widely circulated and patronized.

As found in this study, these myths and misconceptions about COVID-19 being a disease for the aged served as a risk attenuator for the younger generation. This negatively affected uptake of COVID-19 preventive protocols such as washing of hands, use of alcohol-based hand sanitizers and wearing of face/nose masks. In Ghana's response to COVID-19 one thing seems missingsurveillance system to assess, detection and quickly respond to myths and misconceptions especially on social media. It therefore took a very long time for such misconceptions to be brought to the attention of public health authorities. The World Health Organization (WHO) has recognized rumors, myths and misconceptions as a new threat to disease surveillance, outbreak investigation, and prevention (WHO, 2018). There is therefore the need to incorporate a system to monitor misconceptions in designing a surveillance system and managing disease outbreaks such as COVID-19. This is necessary throughout the public health intervention as this study showed that the amount and nature of myths and misconceptions keep changing as the disease evolves in the country.

Attributing COVID-19 to radiations produced by $5 \mathrm{G}$ technology is not biologically plausible. Coronavirus is spread through respiratory droplets when an infected person sneezes, coughs, or speaks (Guo et al., 2020). It can also be spread by touching contaminated surfaces. Viruses cannot travel on radio waves, mobile networks, or through wireless internet. However, this was widely held by adherents of Christian religion because of linkage to the biblical end times. The flood of this information on social media made effective communication harder for public health authorities. In a country where over $70 \%$ of the population are Christians, these myths presented COVID-19 more as a religious battle than a biomedical one. So biomedical remedies such as use of face masks, regular washing of hands and social distancing were deemed ineffective. As a result, some churches decided to defy government ban on religious gathering and held communion services increasing the risk of exposure to their congregants.

One of the main barriers to containment of the outbreak was the reintegration of recovered COVID-19 patients as they experience stigmatization and discrimination. This attitude toward COVID-19 recoveries emanated from the misconception about post recovery transmission of the infection. From the perspective of those infected, pressure of the "social disease" can outweigh the biological burden of the infection (Singer, 2009). More education is required to improve knowledge about COVID-19. The use of social influencers such as religious leaders to provide social and psychological support to those stigmatized and provide education can help demystify this concern. Developing a policy for community engagement during emergencies with consideration for the population dynamics would be necessary. Also relevant for the success of interventions during outbreaks such as COVID-19, is the media. It is, therefore, necessary for government to team up with the media to support public health responses such as providing culturally sensitive, simple, consistent and clear messages. These myths and misconceptions circulating in social media challenges will go beyond COVID-19. It is therefore necessary to develop a national policy on how to prevent, assess and detect misconceived information to prevent its negative effects on management of national public health emergencies in future.

The occurrence of COVID-19 on election year in Ghana presented an opportunity for people to use the pandemic for political mischief. This therefore put the incumbent government under intense pressure with a lot of uncoordinated interventions. The desire to manage COVID-19 related information created a gap which was filled by misconceptions and disinformation. The forming of a parallel COVID-19 team from the government team resulted in crowding of information in social media, depicting varying views from the two teams. This created mistrust among some Ghanaians on the veracity of the information from government. This therefore created a fertile environment for misconception to strive. Approaching public health emergencies as national issues with multi-political team could help address this challenge in future. Again, allowing the existing public health structure to lead the response to the public health will minimize over-politicization and reduce the mistrust witnessed in Ghana's response to COVID-19. As noted by Viswanath (2020) public health communication relies heavily on three principles-transparency, reliability, and trust. The breakdown of any of these principles creates room for misconception to flourish with potential negative consequences on the public health intervention. 


\section{CONCLUSION}

Social media platforms provide an incredible opportunity to share information quickly across the globe and was widely used to spread COVID-19 information. However, COVID-19 misconceptions and misinformation are widespread and cover the course of the condition. These myths necessitate culturally sensitive health communication strategies that take into account local perceptions of COVID-19 in order to tackle the circulation of misconceived messages about the pandemic in Ghana.

\section{DATA AVAILABILITY STATEMENT}

The original contributions presented in the study are included in the article/supplementary material, further inquiries can be directed to the corresponding author.

\section{REFERENCES}

Adongo, P. B., Philip Teg-Nefaah, T., Asampong, E., Ansong, J., Robalo, M., and Adanu, R. M. (2017). Health workers perceptions and attitude about Ghana's preparedness towards preventing, containing, and managing Ebola virus disease. BMC Health Serv. Res. 17, 1-15. doi: 10.1186/s12913-017-2225-0

Agyepong, I. A. (2014). A systems view and lessons from the ongoing Ebolaa virus outbreak in West Africa. Ghana Med. J. 48, 168-172. doi: 10.4314/gmj.v48i3.9

Birt, L., Scott, S., Cavers, D., Campbell, C., and Walter, F. (2016). Member checking: a tool to enhance trustworthiness or merely a nod to validation? Qual. Health Res. 26, 1802-1811. doi: 10.1177/1049732316654870

Bowling, A. (2014). Research Methods in Health: Investigating Health and Health Service, 4th Edn. England: Open University Press.

CDD (2020). Double-Edged Sword? Ghanaians See Pros, Cons of Social Media, Want Access but Not Fake News. Afro Barometer Accra: Centre for Democratic Development, 366

Edwards, A., Housley, W., Williams, M., Sloan, L., and Williams, M. (2013). Digital social research, social media and the sociological imagination: surrogacy, augmentation and re-orientation. Int. J. Soc. Res. Methodol. 16, 245-260. doi: 10.1080/13645579.2013.774185

Fereday, J., and Muir-Cochrane, E. (2006). Demonstrating rigor using thematic analysis: a hybrid approach of inductive and deductive coding and theme development. Int. J. Qual. Methods 5, 80-92. doi: 10.1177/160940690600 500107

Fung, I.C.-H., Tse, Z. T. H., and, Fu, K.-W. (2015). The use of social media in public health surveillance. Western Pac. Surveill. Response J. 6, 3-6. doi: 10.5365/wpsar.2015.6.1.019

Ghassabi, F., and Zare-Farashbandi, F. (2015). The role of media in crisis management: a case study of Azarbayejan earthquake. Int. J. Health Syst. Dis. Manag. 3, 95-102.

Government of Ghana (2018). Media houses. Available online at: http://www. ghana.gov.gh/index.php/mediacenter/media-houses (accessed September 15, 2020).

Guo, Y. R., Cao, Q. D., Hong, Z. S., Tan, Y. Y., Chen, S. D., Jin, H. J. et al. (2020). The origin, transmission and clinical therapies on Coronavirus Disease 2019 (COVID-19) outbreak- a $\mathrm{n}$ update on the status. Milit. Med. Res. 7, 1-10. doi: 10.1186/s40779-020-00240-0

Gyimah-Boadi, E. (2018). Making Democracy Work for the People: Reflections on Ghana's 25-Year Journey Towards Democratic Development. Krontine Akwamu Lecture Series. Ghana Center for Democratic Development.

Hageman, J. R. (2020). The Coronavirus Disease (2019) (COVID-19). Pediatr. Ann. 49:e99-100. doi: 10.3928/19382359-20200219-01

Jin, Y., Liu, B. F., and Austin, L. L. (2014). Examining the role of social media in effective crisis management: the effects of crisis origin, information

\section{ETHICS STATEMENT}

Ethical review and approval was not required for the study on human participants in accordance with the local legislation and institutional requirements. The patients/participants provided their written informed consent to participate in this study.

\section{AUTHOR CONTRIBUTIONS}

PT designed the study, participated in data collection and analysis, and prepared the draft of the manuscript. MS designed the study, participated in data collection and analysis, and reviewed the draft manuscript. Both authors read and approved the final manuscript.

form, and source on publics' crisis responses. Commun. Res. 41, 1-12. doi: 10.1177/0093650211423918

Joshi, A., Sparks, R., Karimi, S., Yan, S. L. J., Chughtai A. A., Paris. C., et al. (2020). Automated monitoring of tweets for early detection of the 2014 Ebola epidemic. PLOS ONE. 15, 1-10. doi: 10.1371/journal.pone. 0230322

Kaplan, A., and Mazurek, G. (2018). "Social Media," in Handbook of Media Management and Economics, 2nd Edn, eds A. B. Albarran, B. I. Mierzejewska, J. Jung (London: Routledge). doi: 10.4324/9781315189918-17

Kasperson, R. E., and Kasperson, J. X. (1996). The social amplification and attenuation of risk. Ann. Am. Acad. Polit. Soc. Sci. 545, 95-105. doi: 10.1177/0002716296545001010

Kasperson, R. E., Renn, Q., Slovic, P., Brown, H. S., Emel, J., Goble, R., et al. (1988). The social amplification of risk: a conceptual framework."Risk Anal. 8, 177-187. doi: 10.1111/j.1539-6924.1988.tb01168.x

Kass-Hout, T. A., and Alhinnawi, H. (2013). Social media in public health. Br. Med. Bull. doi: 10.1093/bmb/ldt028

Kozinets, R. V. (2015). Netnography: Redefined. London: Sage. doi: 10.1002/9781118767771.wbiedcs067

Lauer, S. A., Kyra, H., Grantz, Qifang Bi, G., Jones, F. K., Zheng, Q., et al. (2020). The incubation period of coronavirus disease 2019 (COVID-19) from publicly reported confirmed cases: estimation and application. Ann. Int. Med. 12, 1-13. doi: 10.7326/M20-0504

Little, P., Mark, M., Beth, S., Tammy, T., Sophie, J., Gerry, L., David, R., et al. (2016). Effectiveness of steam inhalation and nasal irrigation for chronic or recurrent sinus symptoms in primary care: a pragmatic randomized controlled trial. CMAJ. 188, 940-949. doi: 10.1503/cmaj.160362

Mian, Q., Masumbuko Claude, K., Underschultz, J., and Hawkes, M. (2019) 50 Ebola epidemic in war-torn eastern democratic Republic of Congo 2018: rapid assessment of knowledge, attitudes, and practices. Paediatr. Child Health. doi: $10.1093 / \mathrm{pch} / \mathrm{pxz} 066.049$

Moorhead, S. A., Hazlett. D. E., Harrison, L., Carroll, J. K., Irwin, A., and Hoving, C. (2013). A new dimension of health care: systematic review of the uses, benefits, and limitations of social media for health communication. J. Med. Internet Res. 15, 1-17. doi: 10.2196/jmir.1933

Myjoyonline (2018). Ghana's mobile phone subscribers to hit $40 \mathrm{~m}$ by 2020. 19 March. Available online at: https://www.myjoyonline.com/business/ghanasmobile-phone-subscribers-to-hit-40m-by-2020-report/ (accessed February 12, 2021).

National Communications Authority (2017). Authorised FM radio stations as at third quarter of 2017. Available online at: https://www.nca.org.gh/industrydata-2/authorisations-2/fm-authorisation-2/ (accessed October 1, 2020).

Republic of Ghana (1996). GHS_ACT525 Copy.Pdf. Accra.

Republic of Ghana (2020). Imposition of Restrictions Act 2020. Ghana. 
Sasu, D. D. (2020). Number of active social media users in Ghana 2017-2020. Statista. 2020. Available online at: https://www.statista.com/statistics/1171445/ number-of-social-media- users-ghana/ (accessed September 12, 2020).

Singer, M. (2009). Pathogens gone wild? medical anthropology and the 'Swine Flu' pandemic. Med. Anthropol. Cross Cult. Stud. Health Illness. doi: 10.1080/01459740903070451 AQ vol

Tabong, P.T.-N., Bawontuo, V., Dumah, D. N., Kyilleh, J. M., K., and Yempabe, T. (2018). Premorbid risk perception, lifestyle, adherence and coping strategies of people with diabetes mellitus: a phenomenological study in the Brong Ahafo Region of Ghana. PLoS ONE 13:e0198915. doi: 10.1371/journal.pone.0198915

Teddlie, C., and Tashakkori, A. (2010). "Overview of contemporary issues in mixed methods research," in Handbook of Mixed Methods in Social and Behavioral Research, 2nd Edn, eds C. Teddlie and A. Tashakkori (Thousand Oaks, CA: Sage), 1-41. doi: 10.4135/9781506335193.n1

The Constitution of Ghana (1992). The Constitution of the Republic of Ghana, Vol. 1. Accra: Ghana Assembly Press.

Viswanath, K. V. (2020). Applied risk communication for the 21st century. Harvard T.H CHAN School of Public Health. 2020. Applied Risk Communication for the 21st Century. Available online at: https://www. hsph.harvard.edu/ecpe/programs/applied-risk-communication-for-the-21stcentury/
Wang, K-W., Gao, J., Wang, H., Wu X. L., Yuan, Q. F., Guo, F. U., et al. (2020). Epidemiology of 2019 novel coronavirus in Jiangsu Province, China after wartime control measures: a population-level retrospective study. Travel Med. Infect. Dis. 35, 1-10. doi: 10.1016/j.tmaid.2020.101654

WHO (2018). Managing Epidemics: Key Facts about Major Deadly Diseases. WHO: Geneva.

Zamawe, F. C. (2015). The implication of using nvivo software in qualitative data analysis: evidence-based reflections. Malawi Med. J. doi: $10.4314 / \mathrm{mmj}$ v27i1.4

Conflict of Interest: The authors declare that the research was conducted in the absence of any commercial or financial relationships that could be construed as a potential conflict of interest.

Copyright $\odot 2021$ Tabong and Segtub. This is an open-access article distributed under the terms of the Creative Commons Attribution License (CC BY). The use, distribution or reproduction in other forums is permitted, provided the original author(s) and the copyright owner(s) are credited and that the original publication in this journal is cited, in accordance with accepted academic practice. No use, distribution or reproduction is permitted which does not comply with these terms. 